\title{
SATISFACCIÓN DE USUARIOS EN CONSULTA EXTERNA DE HOSPITALES PÚBLICOS DE LA REGIÓN ICA, 2018.
}

\author{
QUALITY OF SERVICE IN EXTERNAL CONSULTATION OF PUBLIC HOSPITALS \\ OF THE ICA REGION, 2018.
}

Morón-Valenzuela Julia Cecilia'.

1. Universidad Nacional San Luis Gonzaga. Ica, Perú.

DOI: https://doi.org/10.35563/rmp.v8i3.196

\section{Correspondencia:}

Morón Valenzuela Julia Cecilia Dirección: Urb Las Palmeras $4^{\circ}$ etapa nueva A-4

Número de celular: 963047754 ORCID: 0000-0002-1977-3383 Correo Electrónico:

ceciliamoron2@gmail.com ceciliamoronvalenzuela@hotmail.com
Recibido: $17-08-2019$

Aceptado: 20 - $09-2019$

Publicado: 22 - 09 - 2019

\section{Sr. Editor:}

Según lo leído en el artículo original de Becerra Canales, Bladimir (1). La satisfacción de los usuarios es uno de los problemas más comunes en el sector público debido al gran volumen de pacientes atendidos evidencian que la satisfacción más baja se presenta en el Hospital Regional de Ica $(55,8 \%)$ y el más alto nivel en el Hospital Apoyo de Nasca; este resultado se debe a la distancia y equipos que diferencia a estas Instituciones Hospitalarias. Cabe resaltar el hecho mencionado por Lorenza Vía (2): que el estado promueve la participación de la comunidad en la gestión de los servicios públicos de salud. Es decir que toda persona tiene derecho a la recuperación, rehabilitación y promoción de su salud mental. Sin embargo, frente a los distintos instrumentos empleados para medir la satisfacción de los usuarios hasta el momento no se controla la problemática haciendo suponer que no son suficientes para tomar medidas correctivas.

Según Ariza y colaboradores: Las variables más importantes que explican la satisfacción global de los usuarios son: la opinión del tiempo dedicado por el médico, el que escuche los problemas, la talla, lo cual corresponde al acto médico; la facilidad para hacer trámites, la organización del hospital y los horarios adecuados de consulta, que corresponden a la organización (3).

Frente al resultado obtenido por el investigador Bladimir Becerra (1) cabe precisar que los usuarios externos atendidos en el Hospital Regional presentan características heterogéneas debiéndose haber considerado las referencias que recibe este hospital, convirtiéndose el traslado de un lugar a otro un factor negativo y significativo para medir su satisfacción; situación que no se refleja en el Hospital de Apoyo de Nasca donde las características de la población es más homogénea y por ello no hay mucha dificultad en el acceso a la atención por ello el investigador obtuvo mejor resultado en este grupo investigado.

Asimismo, el investigador señala que el tiempo de espera prolongado, los trámites administrativos burocráticos y el incumplimiento del horario de atención por parte del personal de salud, constituyen las principales causas de insatisfacción de los usuarios externos en los hospitales de la región Ica. Frente a lo mencionado Arroyo menciona otras barreras en un contexto más actual como son la falta de tiempo y el maltrato del personal de salud, aumentaron su presencia en el mismo lapso del $11 \%$ al $23.9 \%$. En otras palabras, se habría dado un desplazamiento en la problemática del acceso a la atención de la salud, en que las barreras principales habrían pasado de los problemas económicos al tema de la calidad del servicio, sin que eso signifique que haya desaparecido evidentemente la falta de dinero como razón de no consulta (4).

Angulo (2018) sostiene que el servicio hospitalario todavía no llega a superar las expectativas de los usuarios, existiendo un trabajo pendiente que hacer referido a la mejora de la calidad en la atención (5). Entonces podemos deducir que el sistema de salud en nuestro país tanto MINSA como Es Salud tienen una desaprobación mayoritaria.

Podemos contribuir con el control de esta problemática en el sentido que las autoridades del Ministerio de Salud debe desarrollar una serie de capacitaciones con énfasis en el personal de salud a fin de que tengan capacidades y actitudes como empatía, amabilidad, respeto a cada paciente que llegue al centro hospitalario; asimismo podemos sugerir a las autoridades a que tengan mayor cuidado con la planificación de los servicios de salud, teniendo como premisa que actualmente el seguro integral de Salud cada día tiene mayor cobertura a la población peruana y esto se ve reflejado en el contexto actual que, como ejemplo tenemos que todos los estudiantes universitarios deben contar obligatoriamente con un seguro social, por lo tanto para años futuros existirá mayor demanda de este servicio e incrementará la problemática indagada. 


\section{REFERENCIAS BIBLIOGRÁFICAS}

1. Becerra B. Satisfacción de usuarios en consulta externa de hospitales públicos de la región Ica, 2018. Rev. méd panacea 2018; 3: 89-92

2. Ariza $F$ et al. Nivel de Satisfacción de usuarios de consulta externa en un hospital público, 2014. Rev. Psicología y Salud 2014; 1(24): 97-107.

3. Vía, L. Niveles de satisfacción con la calidad de atención del área de salud percibido por el personal usuario externo de la Marina de Guerra del Perú, callao, 2017. [Tesis de Grado], Universidad Cesar Vallejo.
4. Arroyo, J. La Salud hoy: problemas y soluciones. Colección CENTRUM Coloquios. 2015; 1(1): 17

5. Ángulo - Crespo, G. El Servicio y su relación con la satisfacción al usuario en el Hospital Regional Hermilio Valdizan - Huánuco 2018. [Tesis de Titulación], Huánuco. Facultad de Ciencias Empresariales. Universidad de Huánuco: 2018.

\section{PANACEA
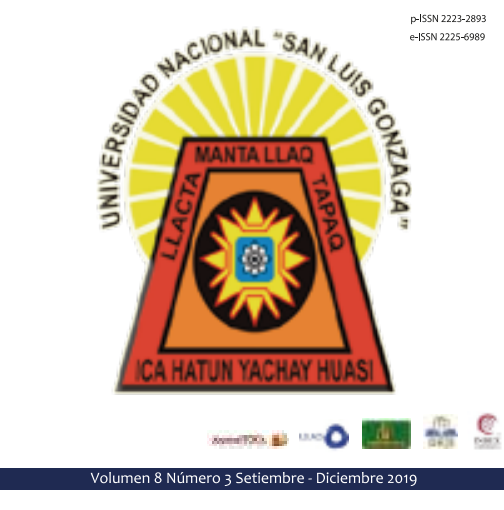